\title{
Group Model Building:
}

\section{Problem Structuring, Policy Simulation and Decision Support}

\author{
David F. Andersen, University at Albany \\ Jac A.M. Vennix, Radboud University Nijmegen \\ George P. Richardson, University at Albany \\ Etiënne A.J.A. Rouwette, Radboud University Nijmegen
}

The authors use the term, "Group Model Building" (Richardson and Andersen 1995; Vennix 1996; 1999) to refer to a bundle of techniques used to construct system dynamics models working directly with client groups on key strategic decisions. We use facilitated face-to-face meetings to elicit model structure and to engage client teams directly in the process of model conceptualization, formulation, analysis, and decision making.

"Group Model Building" (GMB) as we use the term has a cosy, narrow, some might say parochial ring to it. In this brief title, we fail to mention that the models our groups build are always system dynamics models. Furthermore as we discuss below, GMB has much in common with six other named techniques for gaining client involvement in strategic problem finding and problem resolving activities, all using system dynamics models, none of which use the term Group Model Building. We also see our work as sharing many common concerns with the viewpoints expressed in JORS' previous symposium on Problem Structuring Methods. Eden and Ackermann (2006) list four similarities between PSMs: (1) use of a model as a transitional object, (2) increasing the overall productivity of group process, (3) attention to facilitation and effective group process, and (4) appreciation of the significance of facilitation skills. If we were to use Eden and Ackermann's (2006) four points of similarity as a loose definition of PSMs we would have to conclude that GMB is another PSM.

We are probably an example of Westcombe, Franco, and Shaw's (2006) fifth challenge "to design a new PSM that explicitly integrates with a certain approach to hard modelling" while trying to avoid working "simply as a bolt-on to hard modelling". 
The purpose of this viewpoint is to analyse the future of PSMs from the perspective of one particular method, namely, Group Model Building. We start with briefly describing ways to involve clients in the construction of system dynamics models and zoom in on GMB as practised by the Nijmegen and Albany schools. Next we discuss the contribution of the model versus the modelling process to outcomes of GMB. We close with our thoughts on future development of PSMs and GMB.

\section{A short history of client involvement in system dynamics}

System Dynamics was developed by Forrester as a way to focus on corporate policy problems (Forrester 1961). From the start, system dynamics has been aiming at involving clients in the process of model construction. Forrester (e.g. 1961; 1994) has repeatedly emphasized the need to access the mental database of managers in order to be able to construct system dynamics models of strategic problems in business. However, it was not until the second half of the 1970s that the role of client involvement in implementation of model results was more broadly recognised (cf. Greenberger et al. 1976; Roberts 1973). Modellers started working with clients and groups of clients in a variety of ways.

Within system dynamics at least six distinct approaches to client participation (in addition to what we call group model building and other PSMs linked to Soft OR) can be identified: (1) the Reference Group approach (Stenberg 1980), (2) the Strategic Forum (Richmond 1997), (3) the stepwise approach (Wolstenholme 1992), (4) modelling as learning (Lane 1992), (5) strategy dynamics (Warren 1999; 2002; 2005), and (6) the "standard method" of Hines (Otto \& Struben 2004). All of these approaches share much in common and are examples of Friend's (2006) label proliferation tendency as well as Westcombe, Franco, and Shaw's (2006) search for PSMs integrated with hard modelling. Rouwette (2003) compares and contrasts these five participative system dynamics approaches plus GMB and Soft OR approaches along the dimensions of what type of model is built, if and how a preliminary model is used in the process, the size of models built and used, and finally which phases of model building are supported by direct client involvement. The authors on this viewpoint share much in common with practitioners of these and other problem 
structuring approaches in working with groups, but also have significant working differences. Indeed, we share two distinct, but related histories to our work with client groups.

Group Model Building in the Netherlands first emerged in the course of the 1980s. Interactive simulations (what we would now call management flight simulators) had already been worked on before that time, but in the course of the 1980s Vennix and Gubbels started experimenting with the involvement of client groups in the process of model construction (Vennix et al. 1990). In a series of projects several ways of working with client groups emerged (Vennix 1996). Depending on the type of problem these projects resulted in either quantitative or qualitative models. The effects of working directly with models (i.e. interactive simulations) had already been studied by Vennix (1990) and Verburgh (1994). This line of assessment research was continued when work with client groups on model construction emerged and led to thinking about appropriate theories to use in evaluation of Group Model Building interventions and ways empirically to test hypotheses on the effects of working with client groups (cf. Rouwette 2003). In the last decade the work in Nijmegen aimed to go beyond isolated case studies, both by reviewing case reports (Rouwette et al. 2002) and attempting to develop a conceptual framework of GMB effectiveness.

Meanwhile, across the Atlantic, Group Model Building was being co-invented as part of the work of the Decision Techtronics Group (DTG) in Albany, New York. The brainchild of John Rohrbaugh, a social psychologist working in small group processes, DTG brought together a sophisticated understanding of social science research on small group process (Rohrbaugh 1979 and 1981) with an appreciation for the need for facilitation (Quinn et al. 1985) with a variety of OR modelling approaches (Milter and Rohrbaugh 1985; 1988). DTG's modus operandi relied on facilitated face-to-face meetings of client groups with projected computer support in the room. In addition, Rohrbaugh maintained a consistent emphasis on evaluating the effectiveness of what DTG did, reporting such results in the published literature (McCartt and Rohrbaugh 1989; 1995). 
Initially system dynamics modelling was envisioned as one of a portfolio of modelling approaches that DTG offered to client groups. Working with the then new STELLA software, Richardson worked with the DTG team to produce the first exemplar of what we now call Group Model Building at Albany (Reagan-Cirincione et al. 1991). A story accompanies this first project. Andersen was engaged in a running debate with Rohrbaugh over whether or not it was even possible to construct system dynamics models while interacting with a client group. Andersen maintained that the formulation and coding of a system dynamics model (at that time done in DYNAMO) was a task that could not, in principle, involve clients. Rohrbaugh persisted in demonstrating through several pilot projects (typically involving having the facilitation and modelling team work through the night) that such group modelling projects were technically feasible. When Richardson, a seasoned system dynamicist, joined the faculty at Albany, Andersen did not have time to warn him of Rohrbaugh's folly before Rohrbaugh invited Richardson to work on the project. Rohrbaugh and Richardson's success launched GMB at Albany. Reflections on that first project which co-mingled the modelling role and the facilitation role led the Albany team to refine its thinking about how to combine five separate roles into a smoothly working team to support group modelling (Richardson and Andersen 1995). Since that time, our practice has involved a cycle of theoretical reflection, practice with clients, and continuing updating of the method.

\section{The Model vs. the Modelling Process in Group Model Building}

While many of our GMB projects can and do end short of the construction of a fully calibrated and running simulation model, the construction of such finished models is the stated aim of classical GMB as we understand it. Hence, in our work we tend to distinguish between the system dynamics simulation model as the end product of our work and the process of working with clients using facilitation to construct that model. The phrase 'the model vs. the modelling process' harks back to a short but significant 1960s note of Forrester's reprinted as the first Archives paper in the System Dynamics Review: Forrester (1985). It is the process that is closest to traditional PSMs. 
That said, Zagonel's (2002; 2004) recent careful observation of group model building (in the Albany tradition) yielded the insight that the system dynamics model created in GMB sessions has a dual identity. On the one hand, Zagonel argued that at some points in the GMB process, the model is viewed by the team and by the client group as a micro-world, allegedly a realistic representation of the external policy environment under study (cf. "virtual worlds" in Sterman, 2000). This view of the model relates neatly to a positivist view of the world with the model replicating a scientifically constructed view of how a given policy system functions "out there". Zagonel posits that at other points in the modelling process the model functions as a boundary object, serving as a socially constructed artefact whose purpose is to help management teams make sense out of the organization in which they are working. This view of the model is closest to Eden and Ackermann's view of the models in PSMs as transitional objects.

Another important feature of having a running simulation model as an integral part of GMB is that all such models impose a considerable amount of formalism and analytic baggage on a group's thinking. For example, all system dynamics models are focused on dynamic behaviour over time, have stocks and flows, identify feedback loops, and require specific parameter values to run. These requirements constitute a two-edged sword. On the one hand, formal requirements to create a final model in a pre-defined form can stifle and block emergent conversation patterns among the client group if the process is not carefully managed. On the other hand, the formal structure of the final models imposes a healthy empirical discipline on the conversation. In addition, building a formal model with the group allows the modelling team to call upon libraries of previous work and to apply sensitivity checks and other cross-checks that can compare managerial views of the policy system with available administrative and other data sets. Richardson (2006) presents one approach to introducing model formalities into the group model building process via the use of concept models. Howick, Ackermann, and Andersen (2006) discuss a number of techniques that can be used to merge cause maps derived from Decision Explorer sessions with the more formal requirements of a system dynamics model. 
Future research and cross-school development

In other viewpoint papers, several conditions necessary for a healthy future and continued use of PSMs are described. Among those are institutes that teach the use of methods, and practitioners willing to share their experiences and access to clients. In addition to these sensible suggestions, we have two broad themes that animate our thinking about the future of GMB as a PSM.

First, we would like to argue here that knowing more of a method's effectiveness is crucial to its continued use. Westcombe, Franco, and Shaw's (2006) viewpoint centres on their belief that research into PSMs is stagnating. The first of their explanations for this lack of progress is a lack of interest by the originators systematically to evaluate their own approaches, resulting in an over-reliance on anecdotic evidence. If the field of PSMs is to have a future then research into its effectiveness is a prerequisite. This would not only imply reflection on theoretical assumptions underlying PSMs (cf. Richardson 1991; Lane 2001a; 2001b; Vriens and Achterbergh 2006), but also empirical research in order to test hypotheses about in what contexts which elements of our approaches will be effective. So far, many of the evaluation studies have been conducted as case studies or action research. Recently Rouwette et al. (2002) have conducted a first meta-analysis of over 100 of these case studies in system dynamics. What is needed, however, is cooperation between those involved in Group Model Building to accumulate data in a systematic manner. Indeed, over the years, the group from Albany and from Nijmegen have used each others' research material (e.g. questionnaires and evaluation designs) in assessment studies of Group Model Building interventions. Only with this type of systematic empirical research will we be able to learn better about the effectiveness of our interventions.

Here PSMs can learn from research conducted on GDSS and Electronic Meeting Systems. Although there is a trend in the PSM community towards evaluation research (McCartt and Rohrbaugh 1995; Mingers 2000; Mingers and Rosenhead 2004), research and knowledge on the effectiveness of GDSS is at a much more advanced stage than is the case with GMB or PSM in general (cf. McGrath and Hollingshead 1994; Rowe and Wright 1999). In our view advancing our research requires closer attention to relevant theories. Although some 
insights in group model building and PSM practice are grounded upon insights in psychology or management science, there are few attempts to relate context, process and outcome of modelling in a consistent way (cf. Richardson, Andersen, Maxwell and Stewart 1994; Rouwette 2003).

A second broad theme centres on continuing to share practice and learning from other schools of practice under the broad umbrella of PSM. Westcombe, Franco, and Shaw (2006) have sketched a number of the problems inherent in teaching and learning a craftbased body of knowledge and skills. We add to their suggestions for improving practice a drive to publish the details of our craft in terms of small "scripts" of behaviour that are crafted into day-long agendas for working with client groups (e.g., Andersen and Richardson 1997). In addition, we seek to publish detailed accounts of full encounters, illustrating how pre-planned scripts played out in the course of a single intervention (LunaReyes et al. 2005; Rich \& Gonzalez 2006). We especially look forward to the publication of cogent accounts of how facilitators and modellers alike ad lib their performances, like jazz musicians responding to rhythms and themes arising from other team members and clients alike.

But in addition to publishing the "how to" of our own craft and seeking via apprenticeships, visiting, and sabbatical opportunities to learn the crafts of others, we feel that it is important to create new modes of practice by reflecting on and integrating perspectives gained from diverse schools of PSMs. Indeed, our initial definitions of group model building blended practice from two groups, one located in the Netherlands and the other across the Atlantic in Albany. More recently, members of the Albany group have been seeking to craft blended approaches to PSMs working with the Management Science group at Strathclyde as well as North American-based scholars working on strategic planning and leadership issues in the public sector (Bryson 2004; Finn 1996). Most recently, this very work, involving much listening and minute testing of assumptions, has yielded a number of preliminary insights and publications (Andersen et al. forthcoming and Howick, Ackermann and Andersen 2006). We hope to see similar out-reach efforts pushed forward by others. 
It seems that over the years practitioners in the field of Group Model Building have learned a great deal from practitioners in the field of PSMs like Checkland, Eden, Ackermann, Friend and Hickling. Furthermore, since we have coined and want to use the label "Group Model Building" to refer to our work, we hope to be acknowledged within the larger PSM community as among the group that Friend describes as "some of our $21^{\text {st }}$ century successors [who] will feel motivated to devise fresh labels that may find more immediate resonance with those they seek to help."

\section{References}

Andersen D.F. and G.P. Richardson (1997). Scripts for group model building. System Dynamics Review 13(2): 107-129.

Andersen, D. F., G. P. Richardson, \& J.A.M. Vennix. (1997). "Group Model Building : Adding More Science to the Craft." System Dynamics Review 13(2): 187-201.

Andersen D.F., Bryson J.M., Richardson G.P., Ackermann F., Eden C., and Finn C.B. (forthcoming). "Integrating Modes of Systems Thinking into Strategic Planning Education and Practice: The TPI Approach" Journal of Public Affairs Education.

Bryson, J. M. (2004). Strategic Planning for Public and Nonprofit Organizations, Third Edition. San Francisco, CA: Jossey-Bass.

Eden, C. and Ackermann, F. (2006). "Where Next for Problem Structuring Methods". Journal of the Operational Research Society 57(7): 766-768.

Finn, C. B. (1996). "Utilizing Stakeholder Strategies for Positive Collaborative Outcomes." In C. Huxham, ed., Creating Collaborative Advantage. Thousand Oaks, CA: SAGE: $152-164$. 
Forrester, J. W. (1961). Industrial Dynamics. Cambridge MA, MIT Press; reprinted by Pegasus Communications.

Forrester, J. W. (1985). "'The Model' Versus a Modeling 'Process'." System Dynamics Review 1(1): 133-134.

Forrester, J. W. (1994). Policies, Decisions, and Information Sources for Modeling. Modeling for Learning Organizations. J. D. W. Morecroft and J. D. Sterman. Portland, OR, Productivity Press: 51-84.

Friend, J. (2006). "Labels, Methodologies and Strategic Decision Support". Journal of the Operational Research Society 57(7): 772-775.

Greenberger, M., M.A. Crensen \& B.L. Crissy (1976). Models in the Policy Process. New York: Russell Sage Foundation.

Howick, S., Ackermann F. and Andersen D. (2006) "Linking Event Thinking with Structural Thinking: Methods to Improve Client Value in Projects”. System Dynamics Review 22(2): 113-140.

Lane, D. C. (1992). "Modelling as Learning: A Consultancy Methodology for Enhancing Learning in Management Teams." European Journal of Operational Research 59(1): 64-64.

Lane, D. C. (2001a). "Rerum Cognoscere Causas : Part 1 - How Do the Ideas of System Dynamics Relate to Traditional Social Theories and the Voluntarism/Determinism Debate?" System Dynamics Review 17(2): 97-118.

Lane, D. C. (2001b). "Rerum Cognoscere Causas : Part II - Opportunities Generated by the Agency / Structure Debate and Suggestions for Clarifying the Social Theoretic Position of System Dynamics." System Dynamics Review 17(4): 293-309.

Luna-Reyes, L., I. Martinez-Moyano, T. Pardo, A. Cresswell, D. Andersen, and G.P. Richardson (2005). "Group Modeling of IT-Based Innovations in the Public Sector.” International System Dynamics Conference, Boston, MA July 2005. 
Martinez I.J. and G.P. Richardson. (2001). Best practices in system dynamics modelling. Proceedings of the 19th International Conference of the System Dynamics Society Atlanta, Georgia.

McCartt, A.J. and J. Rohrbaugh. 1989. Evaluating Group Decision Support System Effectiveness: a Performance Study of Decision Conferencing. Decision Support Systems 5: 243-253.

McCartt A.T. and J. Rohrbaugh.1995. Managerial opennes to change and the introduction of GDSS: Explaining initial success and failure in decision conferencing. Organization Science 6(5): 569-584.

McGrath J.E. and A.B. Hollingshead (1994). Groups interacting with technology. Thousand Oaks, Sage.

Milter, R. G. and J. Rohrbaugh. 1985. Microcomputers and Strategic Decision Making. Public Productivity Review 9: 175-189.

Milter, R. G. and J. Rohrbaugh. 1988. Judgment Analysis and Decision Conferencing for Administrative Review: a Case Study of Innovative Policy Making in Government. In R.L. Cardy, S.M. Puffer, and J.M. Newman, eds., Advances in Information Processing in Organizations, vol. 3. Greenwich, CT: JAI Press.

Mingers, J. (2000). Variety is the spice of life: combining soft and hard OR/MS methods. International Transactions in Operational Research 7: 673-691.

Mingers, J. and J. Rosenhead (2004). Problem structuring methods in action. European Journal of Operational Research 152: 530 - 554.

Otto, P. A. and J. Struben (2004). "Gloucester Fishery : Insights from a Group Modeling Intervention." System Dynamics Review 20(4): 287-312.

Quinn R, J Rohrbaugh and MR McGrath. (1985). Automated decision conferencing: How it works. Personnel 62 (6): 49-55. 
Randers J, 1977 The potential in simulation of macro-social processes, or how to be a useful builder of simulation models. Gruppen for Ressursstudier, Oslo, Norway.

$\underline{\text { Reagan-Cirincione, P., S. Schuman, et al. (1991). "Decision Modeling : Tools for Strategic }}$ Thinking." Interfaces 21: 52-65.

Rich, E., \& Gonzalez, J. J. (2006). "Maintaining Security and Safety in High-threat Eoperations Transitions." Paper presented at the 39th Hawaii International Conference on System Science, Kauai, Hawaii.

Richardson, G.P. (1991). Feedback Thought in Social Science and Systems Theory. Philadelphia: University of Pennsylvania Press. Reprinted by Pegasus Communications, 1999.

Richardson, G. P. (2006). "Concept Models." Proceedings of the 2006 International Conference of the System Dynamics Society, Nijmegen, The Netherlands. Albany, NY: System Dynamics Society.

Richardson, G. P. and D. F. Andersen (1995). "Teamwork in Group Model Building." System Dynamics Review 11(2): 113-137.

Richardson, G. P., J. A. M. Vennix, et al. (1994). Model Building for Group Decision Support: Issues and Alternatives in Knowledge Elicitation. Modeling for Learning Organizations. J. D. W. Morecroft and J. D. Sterman. Portland, Oregon, Productivity Press.

Richmond, B. M. (1997). "The "Strategic Forum" : Aligning Objectives Strategy and Process." System Dynamics Review 13(2): 131-148.

Roberts, E. B. (1973). "Strategies for Effective Implementation of Complex Corporate Models." TIMS-ORSA Interfaces 8(1, part 1): 26-33.

Rohrbaugh J. (1979). Improving the quality of group judgment: Social judgment analysis and the Delphi technique. Organizational Behavior and Human Performance 24: 73-92. 
Rohrbaugh J. (1981). Improving the quality of group judgment: social judgment analysis and the nominal group technique. Organizational Behavior and Human Performance 28: 272-288.

Rouwette, E. A. J. A. (2003). Group Model Building as Mutual Persuasion. PhD Dissertation, Radboud University Nijmegen, Nijmegen: Wolf Legal Publishers.

Rouwette E.A.J.A., J.A.M. Vennix M and T. van Mullekom (2002). Group model building effectiveness: A review of assessment studies. System Dynamics Review 18(1): 545.

Rouwette, E. A. J. A. and J. A. M. Vennix. (forthcoming) System dynamics and organisational interventions, Systems Research and Behavioural Science, No. 23(4), 2006.

Rosenhead J. and J. Mingers (Eds.) (2001). Rational analysis for a problematic world revisited. Problem structuring methods for complexity, uncertainty and conflict. Chichester: Wiley.

Rowe G, Wright G. 1999. The Delphi technique as a forecasting tool: issues and analysis. International Journal of Forecasting 15: 353-375.

Stenberg, L. (1980). A Modeling Procedure for the Public Policy Scene. Elements of the System Dynamics Method. J. Randers. Cambridge MA, Productivity Press: 257288; reprinted by Pegasus Communications.

Vennix JAM. 1990. Mental models and computer models: Design and evaluation of a computer-based learning environment for policy making. Unpublished doctoral dissertation, University of Nijmegen.

Vennix, J.A.M. (1996). Group model building: Facilitating team learning using system dynamics. Chichester, Wiley.

Vennix, J.A.M. (1999). Group model-building: Tackling messy problems. System Dynamics Review 15(4): 379-401. 
Vennix, J.A.M., Gubbels, J.W., Post, D., Poppen, H.J. 1990. A structured approach to knowledge elicitation in conceptual model-building. System Dynamics Review, 6(2), 194-208.

Verburgh L. 1994. Participative policy modelling applied to the health care insurance industry. Unpublished doctoral dissertation, University of Nijmegen.

Vriens, D. and J. Achterbergh, J. The social dimension of system dynamics-based modeling. Systems Research and Behavioural Science, No. 23(4), 2006.

Warren, K. D. (1999). "Dynamics Of Strategy." Business Strategy Review 10(3): 1-16.

Warren, K. D. (2002). Competitive Strategy Dynamics. United Kingdom, Wiley.

Warren, K. D. (2005). Improving strategic management with the fundamental principles of system dynamics. System Dynamics Review 21(4): 329-350.

Westcombe, M., Franco, L.A. and Shaw, D. (2006). "Where Next for PSMs - A Grassroots Revolution?". Journal of the Operational Research Society 57(7): 776-778.

Wolstenholme, E. F. (1992). "The definition and application of a stepwise approach to model conceptualization and analysis." European Journal of Operations Research 59(1): 123-136.

Zagonel AA. 2002. Model conceptualization in group model building: A review of the literature exploring the tension between representing reality and negotiating a social order. Proceedings of the 20th International System Dynamics Conference, July 28August 1, 2002, Palermo, Italy.

Zagonel, A.A. (2004). Reflecting on group model building used to support welfare reform in New York state. Unpublished doctoral dissertation SUNY Albany, NY. 